\title{
Silicone Resin to Improve Corrosion Resistance of Zn and ZnFe Coated Steel
}

\author{
M.E.P.Souza ${ }^{1,2}$, E.Ariza ${ }^{2}$, M.Ballester ${ }^{3}$, I.V.P.Yoshida ${ }^{4}$, L.A. Rocha ${ }^{2,5}$, C.M.A.Freire ${ }^{1}$ \\ ${ }^{1}$ Department of Materials Engineering, Faculty Mechanical Engineering, UNICAMP, C.P. 6122, 13083-970, \\ Campinas, São Paulo, Brasil. Tel: +55 1937883313 \\ e-mail: eliziane@fem.unicamp.br, celia@fem.unicamp.br \\ ${ }^{2}$ Research Centre on Interfaces and Surfaces Performance, Campus de Azurém, 4800-058, Guimarães, \\ Portugal. Tel: +351 253510231. \\ e-mail: edith@dem.uminho.pt \\ ${ }^{3}$ Applied Physics Department, Physics Institute, UNICAMP, C.P. 6039, Campinas, São Paulo, Brasil. \\ Tel: +55 1937885383 \\ e-mail: bmarga@terra.com.br \\ ${ }^{4}$ Chemistry Institute, UNICAMP, C.P. 6154, 13083-970, Campinas, São Paulo, Brasil. Tel: 551937883023 \\ e-mail: valeria@iqm.unicamp.br \\ ${ }^{5}$ Department of Mechanical Engineering, University of Minho, Campus de Azurém, 4800-058, Guimarães, \\ Portugal. Tel: +351 253510220 \\ e-mail: lrocha@dem.uminho.pt
}

\section{ABSTRACT}

Chromatation pre-treatments have been widely used to improve galvanized steel corrosion resistance. However, due to the high toxicity of chromate ions, chromatation pre-treatments tend to be banned and, in last years, alternative coating systems are under investigation. Recently, polysiloxanes have been developed for application as coatings. Among them, and due to their specific properties, such as hardness, chemical resistance and hydrophobicity, silicone resins may be considered as promising substitutes for chromatation pre-treatments.

In this work silicone films, obtained from the hydrolysis of a methoxy functional silicone reactive intermediate, were applied on galvanized steel and on steel electroplated with a ZnFe alloy. Electrochemical techniques were used to characterize the degradation behavior of the samples. These consisted on the monitoring of the open circuit potential (OCP), and on the potentiodynamic polarization of the samples, which was performed in a $3 \% \mathrm{NaCl}$ aqueous solution. Additionally, electrochemical impedance spectroscopy (EIS) was used as a complementary technique for the evaluation of the corrosion mechanisms of the coating system. SEM and EDS were employed to inspect the surface of the samples before and after the electrochemical tests. EIS data was fitted to an equivalent circuit from which the electrochemical parameters were obtained.

Results show the protective character of the resin films, when compared with uncovered specimens. The capacitance of the films increased with the immersion time, in accordance to the behavior expected for an organic film. The overall performance of the coating systems appears to be highly dependent on the type of metallic coating applied to the steel. During the first three days of immersion the coatings applied upon galvanized steel showed larger $|\mathrm{Z}|$ values when compared with those applied to the electroplated steel, indicating a superior corrosion resistance of the former. However, after that time, an abrupt drop of $|\mathrm{Z}|$ is observed in the film applied on galvanized steel. In comparison, the coating system involving ZnFe alloy evidences a better stability throughout the immersion time.

Palavras chaves: Silicone Resin; Zinc Alloy Coatings; Electrochemical Behaviour.

\section{INTRODUCTION}

Painting of metallic surfaces constitutes an efficient way to provide protection and corrosive prevention for these surfaces. An industrial coating system may consist of several layers each one having different functions. A chemical-conversion coating of chromate or phosphate is often applied initially to provide a substrate of superior adherence. A primer coating of good surface adherence and inhibitive 
properties may be required; these improve the durability of the final topcoats, which have maximum resistance to weather [1-2]].

Nowadays, because of toxicity of chromate ions, environmentally legislation has pressured for to prohibit the pre-treatment with chromates. As a consequence alternative pre-treatments have been researched. Thus, polysiloxanes, materials that own $\mathrm{Si}-\mathrm{O}$ groups, were developed as a viable alternative [$\underline{3}-\underline{4}$ ]. Polysiloxanes are inorganic polymers that contain silicon and oxygen atoms at the principal chain and are characterized for three-dimensional siloxanes net with organic substitutes constituting the units that form the net. At this group the silicone resins can be included. The term "silicone resin" refers to a class of nonlinear, largely silsesquioxane, containing polyorganosiloxanes and formulation there from. Commercial silicone resins can be classified into a DT type, which mainly consist of D and T units, and a MQ type, which comprise $\mathrm{M}$ and $\mathrm{Q}$ units, see figure 1 [므므. The application of silicone chemistry has permitted the development of a simple mechanical treatment for metal surface, these chemicals are easy to handle and nontoxic. Furthermore they provide a better adhesive surface for paints []].

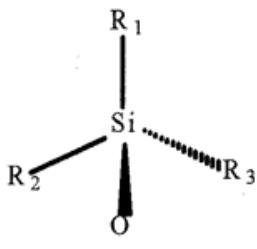

M

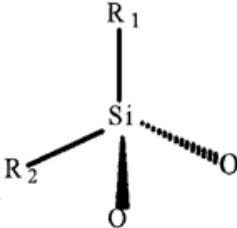

D

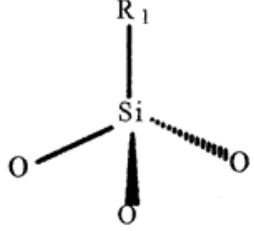

$\mathrm{T}$

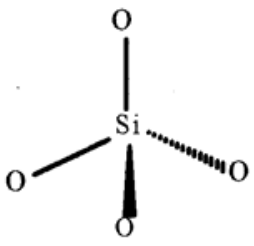

Q

Figure 1: Structures based in the number of oxygen bound to metal atom.

The present paper focused on the valuation of commercial silicone resin (R-3074 - Dow Corning) used to cover $\mathrm{Zn}$ (galvanized) and $\mathrm{ZnFe}$ coated steel without chromate pre-treatments. This resin is a methoxy-functional low-molecular weight, silicone-reactive intermediate. Electrochemical techniques, EIS and potentiodynamic polarization, were used to monitor the behaviour of coating system in a corrosive electrolytic medium. Results were confronted with samples without resin coating to verify the effectiveness of this material.

\section{EXPERIMENTAL}

The experimental procedure can be divided in three parts: Preparation of silicone resins films, application of resin upon the $\mathrm{Zn}$ and $\mathrm{ZnFe}$ coated steel and analysis.

\subsection{Preparation of Silicone Resins}

Sol-gel process was used in the resin films preparation. The intermediate R-3074 was mixed with Dibutylthin diacetate, catalytic, in the proportion of $0.2 \%$ mass. This mixture was agitated for about 15 minutes, until getting an ideal viscosity for application on the substrates.

\subsubsection{Application}

Two substrates were utilised and their characteristics are presented in table 1, none post-plating passivation treatments was made on the substrates.

Before coat application the substrates were cleaned in order to remove any kind of grease. The application was done by a baton that spread the resin upon the plates. A box specially designed and dimensioned was used to obtain resin coating $25 \mu \mathrm{m}$ thick. The curing temperature was $200^{\circ} \mathrm{C}$ for 12 hours. Samples are referred as $\mathrm{Zn}$ and $\mathrm{ZnFe}$, corresponding to the galvanized and electroplated $\mathrm{ZnFe}$ specimens and as $\mathrm{Zn} / \mathrm{R}$ and $\mathrm{ZnFe} / \mathrm{R}$ when they are coated with resin.

Table1: Substrates used and their characteristics.

\begin{tabular}{|c|c|}
\hline Steel substrate & Thickness of Zn coating \\
\hline Galvanized & $5 \mu \mathrm{m}$ \\
\hline Electroplated ZnFe & $5 \mu \mathrm{m}$ \\
\hline
\end{tabular}




\subsubsection{Analyses}

A PGZ 100 Voltalab potentiostat (Radiometer, Denmark), controlled by the Volta Master-4 software, was used in the Electrochemical Impedance Spectroscopy (EIS) experiments. A three-electrode cell arrangement was used in the experiments. The exposed area was $1,86 \mathrm{~cm}^{2}$. The reference electrode was a saturated calomel electrode and the counter electrode was platinum. The electrolyte was a $3 \% \mathrm{NaCl}$ solution and the impedance spectra were ranged from $10^{5}$ to $10^{-2} \mathrm{~Hz}$. The amplitude of a.c. signal imposed was $10 \mathrm{mV}$. Measurements were made at different exposure times, until 3 days of exposure. The impedance spectra were analysed using ZView software and equivalent electrical circuits model had been used to evaluation the behaviour of coatings in corrosive environments.

The open circuit potential (OCP) and the electrochemical polarisation were measured in a Potentiostat PGP 201 (Radiometer, Copenhagen) controlled by the Voltamaster-1 software. The OCP was registered during $60 \mathrm{~min}$ and the potentiodynamic polarisation was determined in a range of -1700 to $0 \mathrm{mV}$ at a scan rate of $2 \mathrm{mV} / \mathrm{s}$. All tests were carried out at ambient temperature in a $3 \% \mathrm{NaC} 1$ solution.

The morphology of coatings was determined using a Scanning Electron Microscopy (SEM). In the same way, the chemical composition was evaluated by an energy dispersive spectrometer (EDS). Surfaces of resin coatings were analysed at initial conditions and after EIS tests.

\section{RESULTS AND DISCUSSION}

In figure 2a) the open circuit potential (OCP) representative of the behaviour of the samples is presented. As it can be observed, after one hour of immersion, the Zn-coated samples exhibit a corrosion potential ca. $200 \mathrm{mV}$ higher than that of the ZnFe-coated samples, this being an indication of a lower tendency for corrosion evidenced by the Zn-coated sample. However, considering the resin coated samples, one can observe that after one hour the corrosion potential is of the same order of magnitude for both the Znand the $\mathrm{ZnFe}$-coated samples. Both samples tend to a stable corrosion potential, which is, however, lower than that of the Zn-coated samples. Nevertheless, it should be referred the dissimilar evolution of the potential curves for the $\mathrm{ZnFe} / \mathrm{R}$ and the $\mathrm{Zn} / \mathrm{R}$ curves. In fact, for the $\mathrm{Zn} / \mathrm{R}$ sample the corrosion tendency appears to increase with the immersion time, as shown by the decrease in potential, while for the $\mathrm{ZnFe} / \mathrm{R}$ sample a slight increase in corrosion potential is observed.
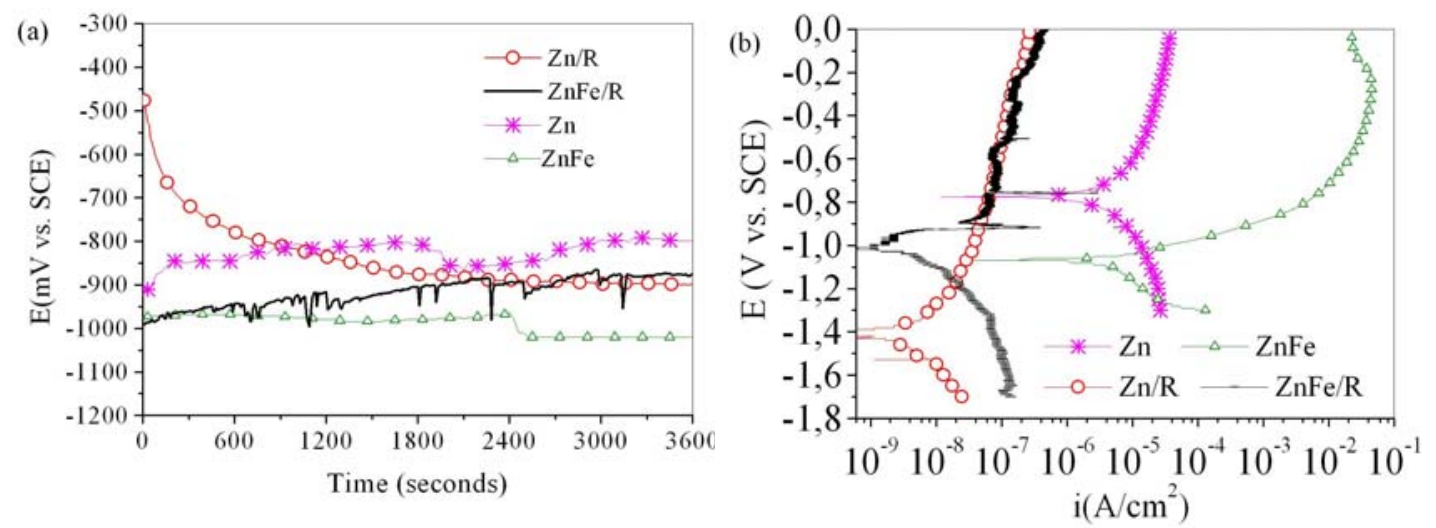

Figure 2: Open circuit potential and polarization curves of uncoated samples and resin-coated systems.

Representative potentiodynamic polarization curves expressing the behaviour of the samples are presented in fig. $2 \mathrm{~b}$. A first remark to be made refers to the $\mathrm{Zn} / \mathrm{R}$ and $\mathrm{ZnFe} / \mathrm{R}$ curves, both displaying a passive plateau characterised by a corrosion current density ranging from $10^{-7}$ to $10^{-6} \mathrm{~A} . \mathrm{cm}^{-2}$. As it can be seen, the passive plateau for the $\mathrm{Zn} / \mathrm{R}$ sample is present for a larger potential range than that of the $\mathrm{ZnFe} / \mathrm{R}$ sample. Also, the passive current densities for the resin coated samples are 2 and 5 decades lower than that of the $\mathrm{Zn}$ and $\mathrm{ZnFe}$ samples, respectively, this being a strong indication of the protective character of the resin.

The monitoring of the time dependence of the electrochemical impedance of the coated samples, exposed to $\mathrm{NaCl}$ solution, allowed the evolution of the corrosion protection character of each coating system to be compared. It is well known that equivalent electrical circuits can be used to explain the electrochemical impedance data obtained by the EIS tests. These models use a combination of resistance, capacitance and other elements which have a clear physical meaning, related with the response of the electrochemical system [8]. In this work a general equivalent electrical circuit model for coating systems was used, as illustrated in

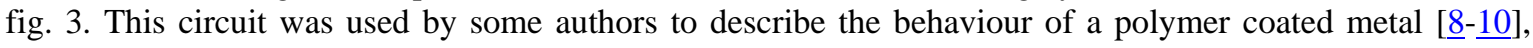


where $R_{e}$ is the electrolyte resistance, $R_{p}$ is the coating pore resistance, $C_{c}$ is the coating capacitance, $R_{c t}$ is the charge-transfer resistance and $\mathrm{C}_{\mathrm{DL}}$ is the double-layer capacitance at the coating/solution interface. All the capacitances shown in the equivalent electrical circuit are mathematically modelled using a constant phase element (сре); this element represents all the frequency dependent electrochemical phenomena. The results from EIS was successful adjusted to this circuit, with the exception of the data obtained in the $\mathrm{Zn} / \mathrm{R}$ samples immersed for one hour of sample, where a simple electrical circuit just with a $R_{e}, C_{c}$ and $R_{p}$ was fitted to the experimental data.

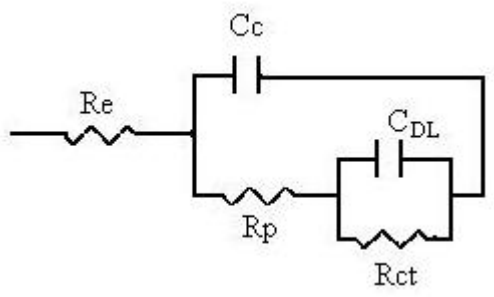

Figure 3: Equivalent electrical circuit

Figure 4 shows results obtained in samples $\mathrm{Zn}$ and $\mathrm{ZnFe}$ in the EIS experiments. As shown in fig 4a, the values of $|\mathrm{Z}|$ for both samples at different times of immersion are in the range $10^{2}-10^{3} \Omega$. A relaxation time observed at the low frequency region, for the third day of exposure, denotes the presence of a degradation process occurring on the samples surfaces caused by the time of immersion, fig. 4b. Sample Zn presents a better behaviour in the first hour of immersion, as shown both by the high $|\mathrm{Z}|$ value and the high phase angle, but the EIS results suggests a degradation of the protective characteristics of the films after 3 days of immersion. In contrast, the ZnFe sample increases the value of $|\mathrm{Z}|$ after three days of immersion, indicating an increase of the protective characteristics of the coating. This behaviour may perhaps be attributed to the blockade of surface pores with corrosion products.

Figure 5 shows the evolution with immersion time of the Bode plots resulting from the EIS tests carried out in the resin coated samples. The first remark to be done refers to the barrier against corrosion provided by these resin coatings. In fact, as it can be seen in fig 5 a) and c), $|\mathrm{Z}|$ values at low frequencies, are several decades higher than that found on the resin uncoated sample $\left(10^{-9} \Omega\right.$ for the $\mathrm{Zn} / \mathrm{R}$ sample, and $10^{-7} \Omega$ to $\mathrm{ZnFe} / \mathrm{R}$ sample), after one hour of immersion. Additionally, as seen in fig $5 \mathrm{~b}$ ) and d), phase angles approaching $90^{\circ}$, at high frequencies, are indicative of a capacitive behaviour to coatings.

It should be referred a distinctive behaviour of the resin-coated samples, depending on the nature of the substrate. In fact, in the $\mathrm{Zn} / \mathrm{R}$ sample the impedance spectra changed from a capacitive nature after one hour of immersion, which is typical of intact coatings, to a spectrum containing two time constants [11]. On the order hand, sample $\mathrm{ZnFe} / \mathrm{R}$ exhibited two time constants since the first hour of immersion, indicating the influence of the $\mathrm{ZnFe} /$ resin interface on the corrosion process. By other words, it might represent an indication of some permeability of the resin from the first moments of immersion. A decrease of $|\mathrm{Z}|$ with immersion time can be observed for the two samples. However for the $\mathrm{Zn} / \mathrm{R}$ sample this fall is more accentuated, mainly after the second day of immersion.
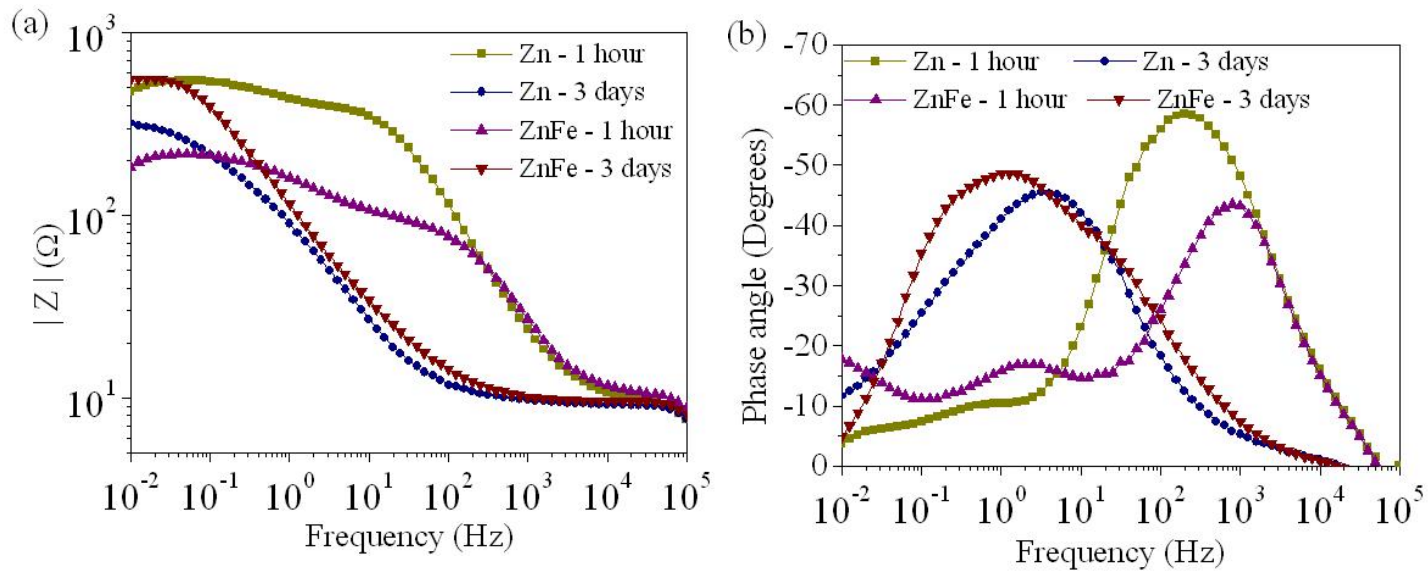

Figure 4: Bode Plots of Zn and ZnFe specimens at different times of immersion. 
Legend for all
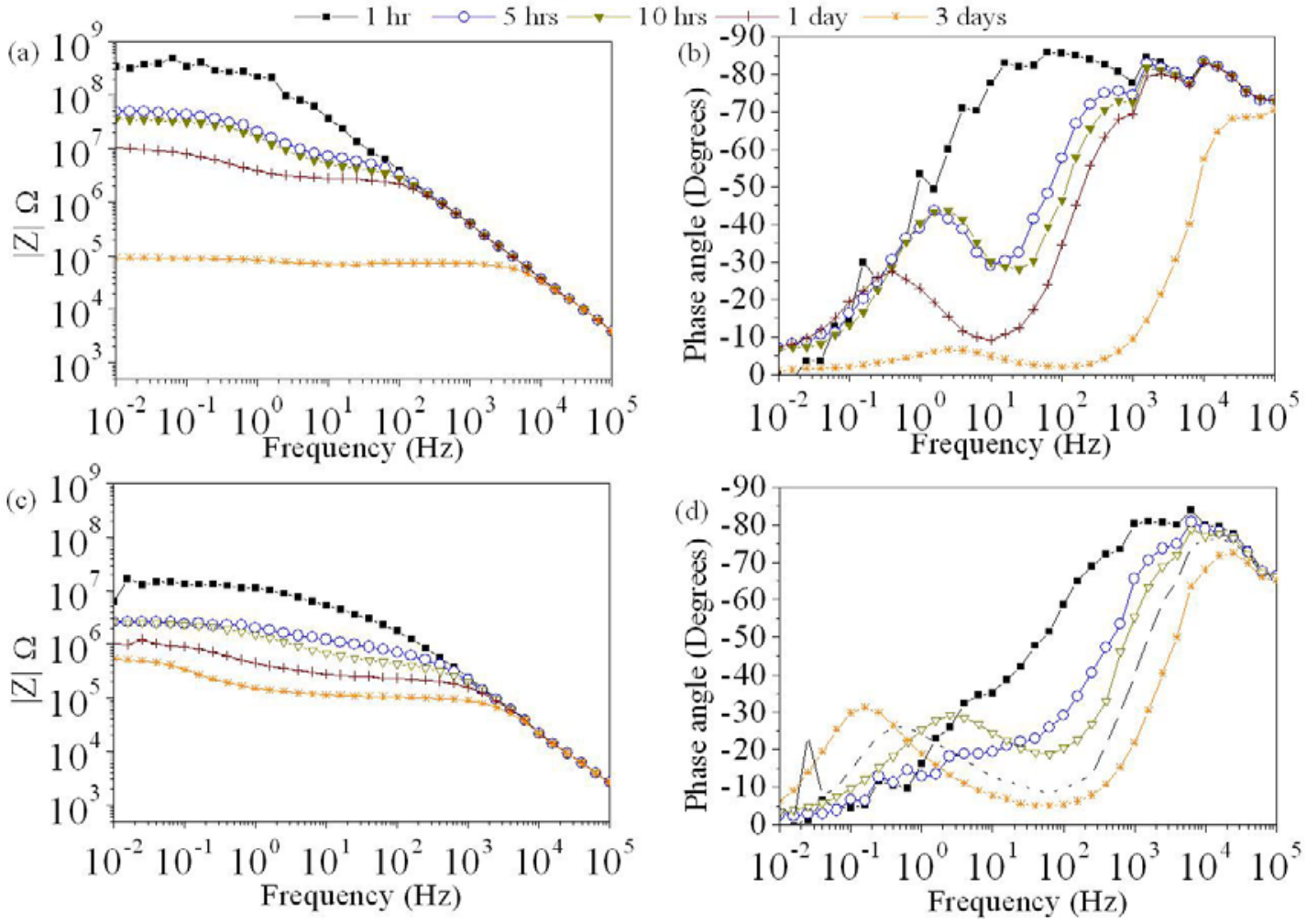

Figure 5: Bode plots of specimens $\mathrm{Zn} / \mathrm{R}(\mathrm{a}-\mathrm{b})$ and $\mathrm{ZnFe} / \mathrm{R}(\mathrm{c}-\mathrm{d})$ at different immersion times.

According to some authors, the evaluation of $\mathrm{C}_{\mathrm{c}}$ can be associated to water uptake or the entry of electrolyte into the coating $[\underline{9}, \underline{11}]$. In fig. 6 a) the dependence of the coating capacitance $\left(\mathrm{C}_{c}\right)$ and of the double-layer capacitance $\left(\mathrm{C}_{\mathrm{DL}}\right)$, with the immersion time is presented. Firstly, the $\mathrm{C}_{\mathrm{c}}$ values for the $\mathrm{Zn} / \mathrm{R}$ and $\mathrm{ZnFe} / \mathrm{R}$ are always lower than the values calculated for the samples without resin, indicating a good protective character of the resin over the substrate. Also, as it can be observed, $\mathrm{C}_{c}$ for the two resin-coated samples maintains very stable, maybe with a slight tendency to increase, throughout the immersion time, this being an indication of the maintenance of good protective properties of the resin coating. The continuous raise of the double-layer capacitance $C_{D L}$, presented in figure $6 \mathrm{~b}$ ), is representative of the increase of the area at which delamination or corrosion occurs [10]. This increase was largest for sample $\mathrm{Zn} / \mathrm{R}$, which indicate this coating system provide the least corrosion protection
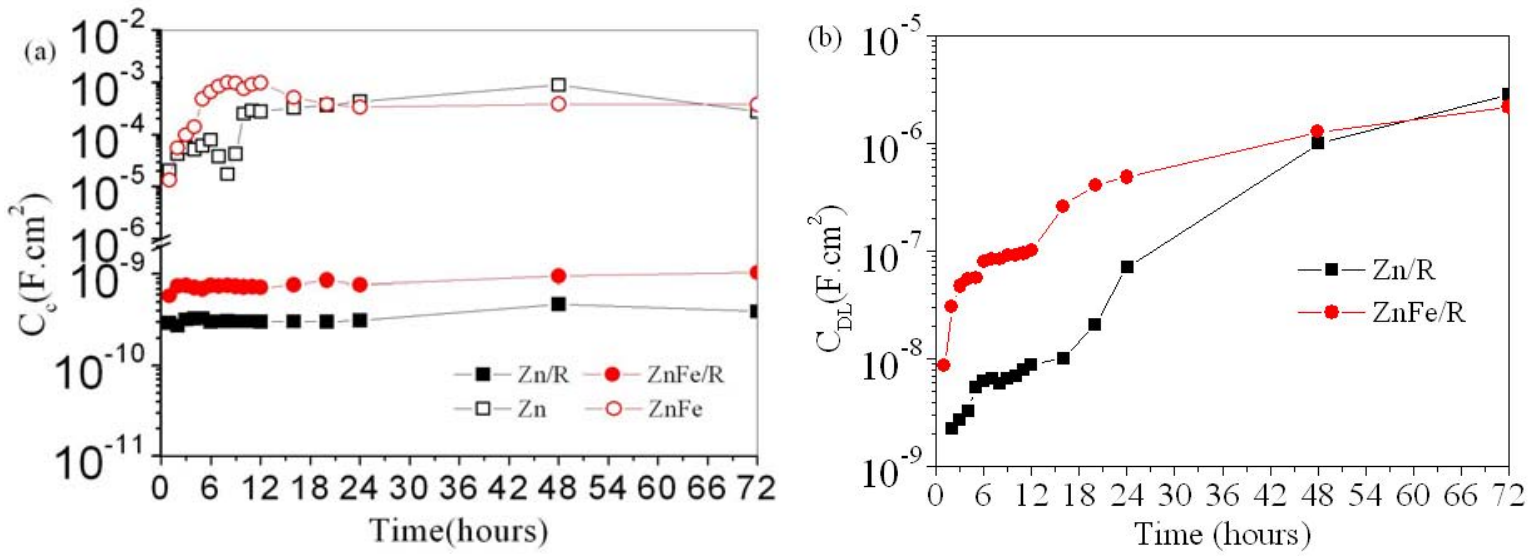

Figure 6: Time dependence of coating capacitance $\left(\mathrm{C}_{c}\right)$ and double-layer capacitance $\left(\mathrm{C}_{\mathrm{DL}}\right)$ in a $3 \% \mathrm{NaCl}$ solution. (a) $\mathrm{C}_{\mathrm{c}}$ of resin coated and uncovered samples; (b) $\mathrm{C}_{\mathrm{DL}}$ of $\mathrm{Zn} / \mathrm{R}$ and $\mathrm{ZnFe} / \mathrm{R}$. 
Figure 7 a) shows the variation of the $R_{p}$ at function of immersion time for all samples. In the first moments of immersion $R_{p}$ for the $Z n / R$ sample is substantially higher than that calculated for the $Z n F e / R$ sample. However, the decrease of $R_{p}$ with the immersion time was found to be more abrupt for the $\mathrm{Zn} / \mathrm{R}$ sample. For both samples the pore resistance stabilizes at a value near $10^{6} \Omega . \mathrm{cm}^{-2}$. In comparison with the systems without resin, the values of $R_{p}$ are bigger until the end of experiments showing that the resin continues protecting the substrate.

The evaluation of the evolution of $\mathrm{R}_{\mathrm{ct}}$ with the immersion time shows that, although the higher $\mathrm{R}_{\mathrm{ct}}$ shown by the Zn/R sample during the first hours of immersion when compared with the ZnFe/R sample, after 3 days the $\mathrm{Zn} / \mathrm{R}$ sample displays a charge transfer resistance more than one decade lower than the $\mathrm{ZnFe} / \mathrm{R}$ sample. Nevertheless, for both resin-coated systems, $R_{c t}$ is much higher for the resin-coated samples than for the samples without the resin coatings.
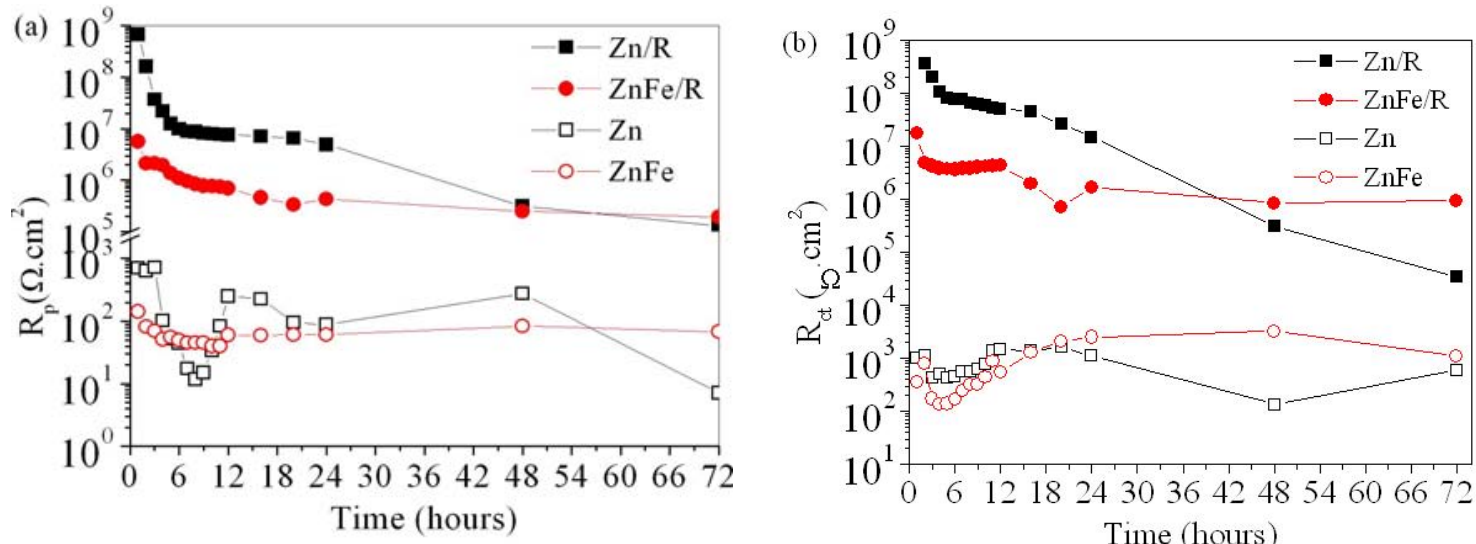

Figure 7: Time dependence of the coating pore resistance $\left(R_{p}\right)$ and charge-transfer tesistance $\left(R_{c t}\right)$, for all samples in a $3 \% \mathrm{NaCl}$ solution.

As referred above, EIS data indicates that absorption of the electrolyte by the resin is likely to occur after some time of immersion. In figure 8, representative SEM micrographs of the surface of the $\mathrm{Zn} / \mathrm{R}$ samples before and after the EIS test are presented. As it can be seen, the surface of the samples appears to be very smooth, and no signs of significant defects are observed before the immersion of the samples in the saline solution. However, after the EIS test, some white spots are observed in the surface, which appears to be due to a slight swell of the resin coating, this being an indication of penetration of the electrolyte into the resin at dispersed spots, resulting in lack of adhesion at those regions, probably due to the de-cohesion of the coating. By EDS it was not possible to identify the presence of any corrosion products at those spots. Consequently, any corrosion products resulting from the reaction of the $\mathrm{Zn}$ substrate with the solution at those spots, are apparently kept at the Zn/resin interface, explaining the de-cohesion of the resin coat.
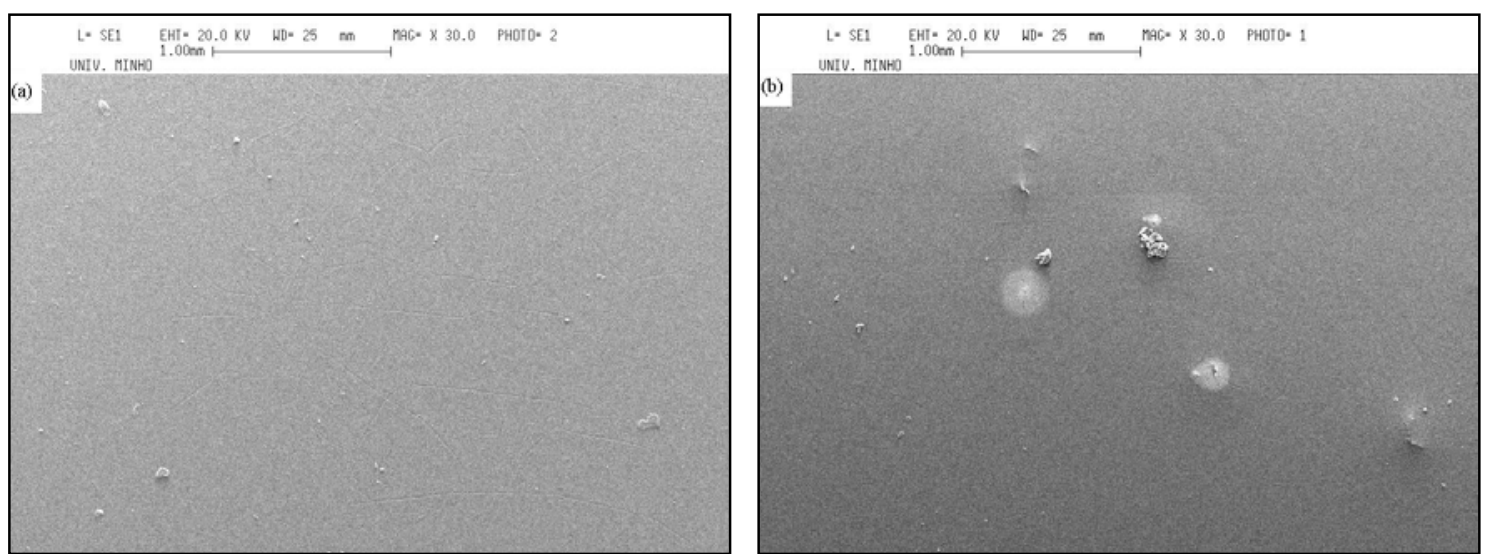

Figure 8: SEM micrographs of surface of sample Zn/R before EIS test (a) and after the EIS test (b).

In fact, both the potentiodynamic polarization and EIS results indicates that the behaviour of the resin-coated samples results from the events happening at the resin/substrate interface. In this aspect, as 
referred above, the $\mathrm{Zn} / \mathrm{R}$ samples, although presenting a superior corrosion resistance in the beginning of the tests, presents a higher tendency to degradation during immersion. In figure 9 cross-sections representative of both resin-coated systems are presented. As it can be seen, in both systems the resin coating appears to be very compact, and no open pores can be detected. However, the observation of the resin/substrate interface reveals a defective adhesion of the resin to the $\mathrm{Zn}$ sample, which might lead to accumulation of electrolyte, in case of its penetration through the coating.
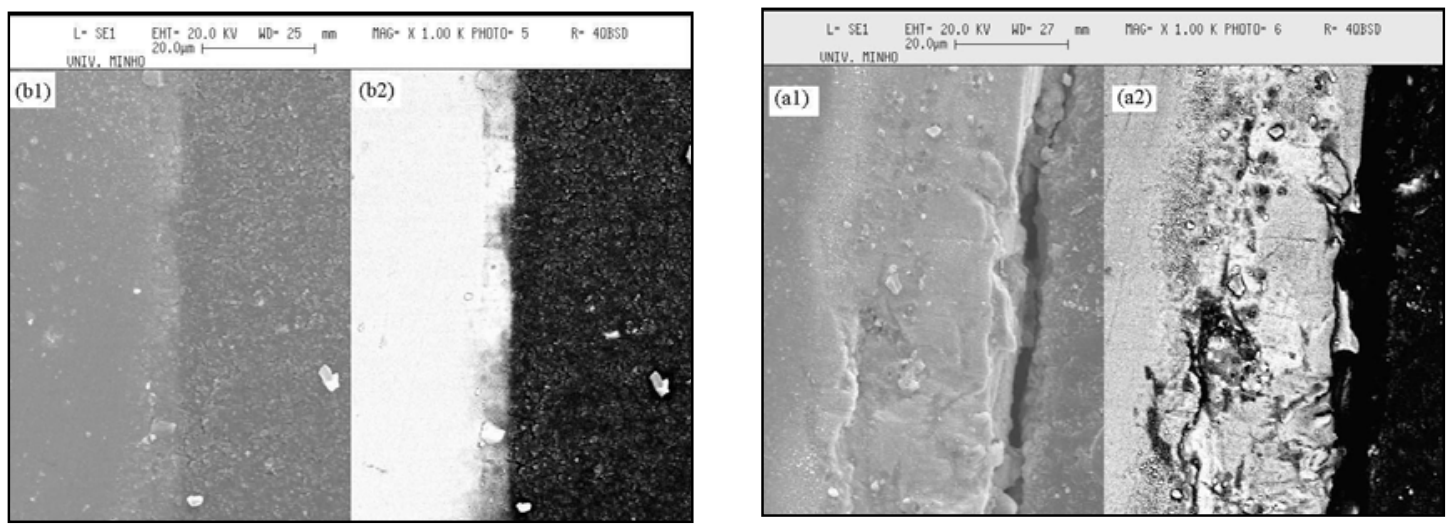

Figure 9: SEM micrographs of the cross section of Zn/R (a) and ZnFe/R (b). 1- Image of secondary electrons. 2- Image of back-scattered electrons.

\section{CONCLUSIONS}

Zn coated steel showed a superior corrosion resistance when compared with the ZnFe coated steel. Additionally, silicone films have shown the ability of providing supplemental corrosion protection to $\mathrm{Zn}$ and $\mathrm{ZnFe}$ coated steel. However, in contrast with the behaviour of the resin-uncoated samples, the performance of the $\mathrm{ZnFe}$ resin-coated samples in contact with a sodium chloride solution becomes better than that of the $\mathrm{Zn}$ resin-coated samples. Penetration of the solution through the resin coating and a defective adhesion of the silicone to the galvanized steel might explain this behaviour.

\section{ACKNOWLEDGEMENTS}

The authors gratefully acknowledge Capes and CNPq for the financial support.

\section{REFERENCES}

[1] CABRAL, E.R., MANNHEIMEN, W.A., Galvanização, sua aplicação em equipamentos elétricos, 1ed, Ao livro técnico S/A, Indústria e comércio, Rio de Janeiro, pp.37, 1979.

[2] JONES, D. A., Principles and prevention of corrosion, 2nd ed., Prentice-Hall Inc, USA, pp.477, 1996.

[3] CHILD, T.F., van OOIJ, W.J, “Application of Silane Technology to Prevent Corrosion of Metals and Improve Paint Adhesion”, Trans IMF, v. 77, n.2, pp. 64-70, 1999.

[4] BECCARIA, A. M., PADELETTI, G., MONTESPERELli, G., CHIARUTTINI, L., “The Effect of Pretreatments with Siloxanes on the Corrosion Resistance of Aluminium in NaCl Solution”, Surface \& Coatings Technology, v. 111, pp. 240-246, 1999.

[5] BANEY, R. H., ITOH, M., SAKAKIBARA, A., SUSUKI, T., “Silsesquioxanes”, Chemical Reviews, v. 95, pp. $1409-1430,1995$.

[6] ARKLES, B., “Commercial Applications of Sol-Gel-Derived Hybrid Materials”, MRS Bulletins, May, pp. 402-407, 2001.

[7] Petrunin, M. A., NAZAROV, A. P., ZAitSEV, R. M., MIKLAILOVSKI, YU. N., "Phase interactions in a system composed of a metal and an anticorrosive siloxanes coating”, Protection of Metals (English translation of Zaschita Metallov), v 26, n 5 (May), pp. 587-592, 1991, 
[8] BONORA, P., DEFLORIAN, F., FEDRIZZI, L., "Electrochemical impedance spectroscopy as a tool for investigation underpaint corrosion”, Electrochimica ACTA, v. 41, n. 7-8 (May-Jun) pp. 1073-1082, 1996.

[9] BAJAT, J. B., MISKOVIC-STANKOVIC, V. B., KACAREVIC-POPOVIC, Z., "The influence of steel surface modification by electrodeposited Zn-Fe alloys on the protective behaviour of an epoxy coating”, Progress in Organic Coatings, v. 47, pp. 49-54, 2003.

[10] McINTYRE, J. M., PHAN, H. Q., "Electrochemical impedance spectroscopy; a tool for organic coatings optimisations”, Progress in Organic coatings, v. 27, n. 1-4 (Jan-Apr), pp. 201-207, 1996.

[11] TSAI, C. H., MANSFELD, F., "Determination of coating deterioration with EIS: Part II. Development of a method for field testing of protective coatings”, Corrosion, v. 49, n. 9 (Sep), pp. 726-737, 1993. 